\title{
Structural integrity assessment and stress measurement of CHASNUPP-1 fuel assembly Part A: under tensile loading condition
}

\author{
Waseem*, Ghulam Murtaza, Ashfaq Ahmad Siddiqui, and Syed Waseem Akhtar \\ Directorate General Nuclear Power Fuel, Pakistan Atomic Energy Commission, PO Box No. 1847, 44000 Islamabad, Pakistan
}

Received: 10 September 2015 / Received in final form: 26 November 2015 / Accepted: 28 January 2016

Published online: 8 April 2016

\begin{abstract}
Fuel assembly of the PWR nuclear power plant is a long and flexible structure. This study has been made in an attempt to find the structural integrity of the fuel assembly (FA) of Chashma Nuclear Power Plant-1 (CHASNUPP-1) at room temperature in air. The non-linear contact and structural tensile analysis have been performed using ANSYS 13.0, in order to determine the fuel assembly (FA) elongation behaviour as well as the location and values of the stress intensity and stresses developed in axial direction under applied tensile load of $9800 \mathrm{~N}$ or $2 \mathrm{~g}$ being the fuel assembly handling or lifting load [Y. Zhang et al., Fuel assembly design report, SNERDI, China, 1994]. The finite element (FE) model comprises spacer grids, fuel rods, flexible contacts between the fuel rods and grid's supports system and guide thimbles with dash-pots and flow holes, in addition to the spot welds between spacer grids and guide thimbles, has been developed using Shell181, Conta174 and Targe170 elements. FA is a non-straight structure. The actual behavior of the geometry is non-linear due to its curvature or design tolerance. It has been observed that fuel assembly elongation values obtained through FE analysis and experiment [SNERDI Tech. Doc., Mechanical strength and calculation for fuel assembly, Technical Report, F3.2.1, China, 1994] under applied tensile load are comparable and show approximately linear behaviors. Therefore, it seems that the permanent elongation of fuel assembly may not occur at the specified load. Moreover, the values of stresses obtained at different locations of the fuel assembly are also comparable with the stress values of the experiment determined at the same locations through strain gauges. Since the results of both studies (analytical and experimental) are comparable, therefore, validation of the FE methodology is confirmed. The stress intensity of the FE model and maximum stresses developed along the guide thimbles in axial direction are less than the design stress limit of the materials used for the grid [ASTM, Standard specification for precipitation hardening nickel alloy (UNSN07718) plate, sheet, and strip for high temperature service, B 670-80, USA, 2013], fuel rod [ASTM, Standard specification for wrought zirconium alloy seamless tubes for nuclear reactor fuel cladding, B 811-02, USA, 2002] and the guide thimble [ASTM, Standard specification for seamless stainless steel mechanical tubing, A 511-04, USA, 2004]. Therefore, the structural integrity criterion of CHASNUPP-1 fuel assembly is fulfilled safely at the specified tensile load.
\end{abstract}

\section{Introduction}

CHASNUPP-1 fuel assembly consists of a $15 \times 15$ square array of fuel rods, spacer grids, guide thimbles, instrumentation tube, and top and bottom nozzles. The 3D model of fuel assembly containing 20 guide thimbles, 204 fuel rods and an instrumentation tube in conjunction with the 8 spacer grids and top and bottom nozzles, has been developed using the Inventor software, and is shown in Figure 1.

\footnotetext{
* e-mail: wazim_me@hotmail.com
}

In fuel assembly, fuel rods are held by spacer grids supports system (springs and dimples) to maintain rod-torod centerline spacing along the entire length of fuel assembly [1]. The material of top and bottom nozzles, instrumentation tube and guide thimbles is SS-321, whereas spacer grids and fuel rod cladding are made up of Inconel-718 and Zircaloy-4, respectively.

The fuel assembly of pressurized water reactor (PWR) bears a variety of loads, such as tensile, compressive, bending, torsional, impact, etc., while undergoing through handling, shipping and reactor operation. The structural strength of the fuel assembly is supplied by the skeleton of the fuel assembly. 


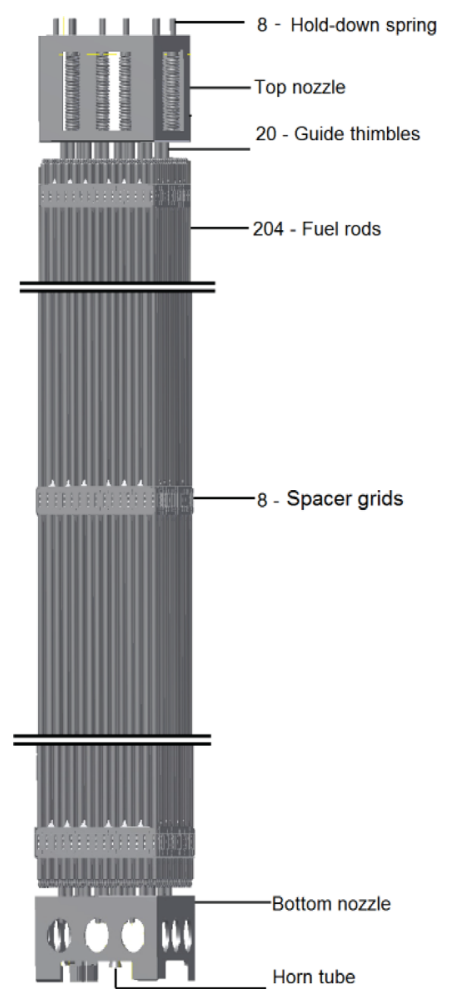

Fig. 1. 3D solid model of CHASNUPP-1 fuel assembly.

The guide thimble tubes are connected with grids by means of spot welds [2]. The top end of the guide thimbles and instrumentation tube are TIG welded with the adapter plate of the top nozzle, while the lower end of the guide thimbles are fastened to the bottom nozzle by bolting.

Previously, we had made study of non-linear buckling analysis of CHASNUPP-1 skeleton and fuel assembly under applied compression load, in order to determine the deformation behavior, stresses and area of the stress concentration [3,4]. Our present study is a part of series of studies which are being conducted in an attempt to contribute towards current research on the design and development work of the PWR fuel assembly. We have now performed the non-linear axial tensile analysis to determine the elastic elongation and assess structural integrity of the fuel assembly under applied axial tensile load of $9800 \mathrm{~N}$ $(2 \mathrm{~g})$ at room temperature. The results obtained through the $\mathrm{FE}$ analysis have been compared with the experimental results, which show good agreement and confirm the validation of $\mathrm{FE}$ methodology.

\section{FE model and computational details}

CHASNUPP-1 fuel assembly possesses symmetry in geometry, material properties and loading conditions. Therefore, in this analysis advantage of symmetry has been taken into account by considering half symmetry of fuel assembly to reduce the size and computational time of the FE model.

The detailed FE model of CHASNUPP-1 fuel assembly, consisting of guide thimbles, fuel rods, spacer grids with

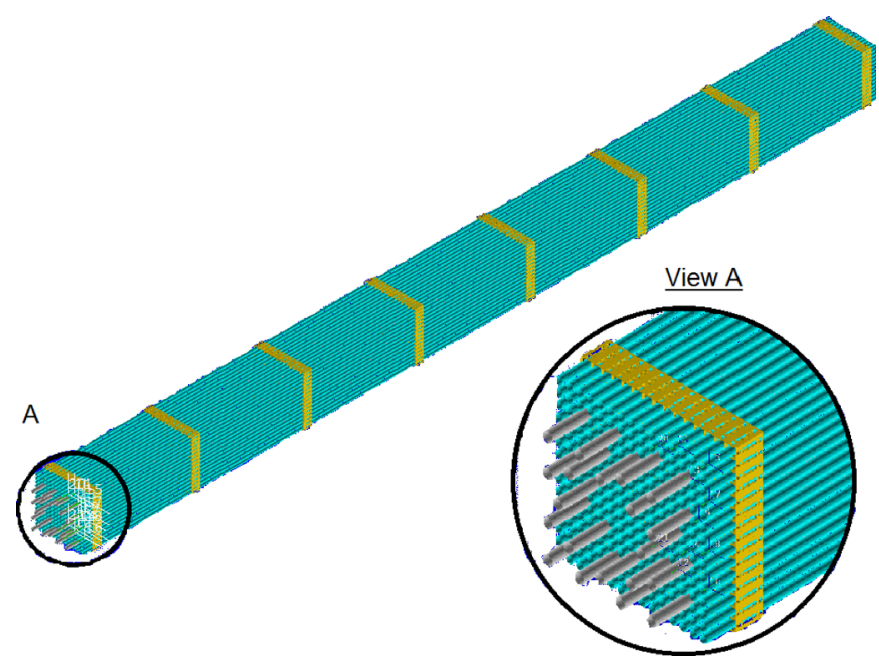

Fig. 2. Model geometry.

supports systems (springs and dimples) and spot welds (diameter $2.4 \mathrm{~mm}$ ) between the guide thimbles and the grid's tabs, has been developed using ANSYS 13.0. FE model has been solved using multi-load step. In the first step, contacts between the grid supports (springs and dimples) and the fuel rods have been developed using nonlinear contact analysis [1]. In the second load step, nonlinear tensile analysis has been performed to determine elastic elongation behaviour and the area of stress concentration of the fuel assembly under the applied fuel assembly handling or lifting load, i.e. $2 \mathrm{~g}$. The mass of CHASNUPP-1 fuel assembly with RCCA is $465 \mathrm{~kg}$. By taking acceleration of $9.81 \mathrm{~m} / \mathrm{s}^{2}$, the load equivalent to $1 \mathrm{~g}$ is $4650 \mathrm{~N}$ and the max. applied load equivalent to $2 \mathrm{~g}$ or $9800 \mathrm{~N}$ at room temperature conditions. The detailed solid model is illustrated in Figure 2.

Shell181 element type is used to create mapped meshing (Quadrilateral Elements). It is a 4-node element with 6degrees of freedom, well suited for linear, large rotation or displacements, and/or large strain non-linear application. After creating the underlying FE model, the flexible surface-to-flexible surface contact pairs have been created using the element types Conta174 and Targe170. The coefficient of friction between fuel rod and grid determined experimentally is taken as 0.35 [5]. The details of FE model are shown in Figure 3.

The entities developed in the FE model are mentioned in Table 1.

The thicknesses of guide thimble, fuel rod and grid, $0.5 \mathrm{~mm}, 0.7 \mathrm{~mm}$, and $0.3 \mathrm{~mm}$, respectively, are defined by giving real constant values. The material properties of guide thimble, fuel rod and spacer grid used in the present FE analysis are given in Table 2.

Simulations of the boundary conditions of CHASNUPP-1 fuel assembly under applied tensile load have been applied as follows:

- to constrain the FE model, all nodes at lower end of the guide thimble have been fixed in all directions;

- to simulate the symmetry boundary conditions, translation of all the nodes at the inside edge of one-half portion 


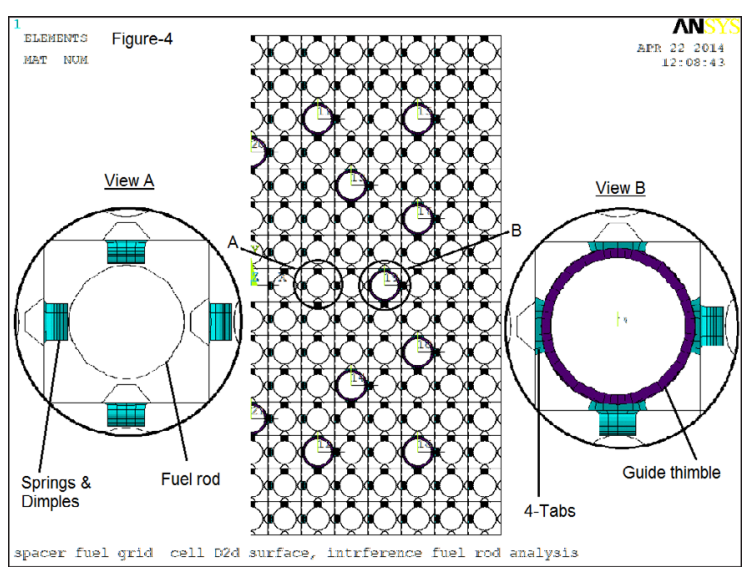

Fig. 3. Element plot of FE model.

Table 1. Entity details of the FE model.

\begin{tabular}{ll}
\hline Entity & Quantity \\
\hline Key points (KP) & 266,989 \\
Lines (L) & 488,897 \\
Areas (A) & 210,232 \\
Nodes (N) & 942,850 \\
Shell181 elements & $1,005,992$ \\
Conta174 elements & 78,336 \\
Targe170 elements & 91,776 \\
\hline
\end{tabular}

Table 2. Material properties of grid, guide thimble and fuel rod.

\begin{tabular}{|c|c|c|c|c|}
\hline Materials & $\begin{array}{l}\text { Yield } \\
\text { strength } \\
\text { (MPa) }\end{array}$ & $\begin{array}{l}\text { Tensile } \\
\text { strength } \\
\text { (MPa) }\end{array}$ & $\begin{array}{l}\text { Modulus of } \\
\text { elasticity } \\
\text { (GPa) }\end{array}$ & $\begin{array}{l}\text { Poisson's } \\
\text { ratio }(\gamma)\end{array}$ \\
\hline $\begin{array}{l}\text { Grid (GH-169A } \\
\text { alloy/ } \\
\text { Inconel-718) }\end{array}$ & $\geq 1034$ & $1520-1700$ & 205 & 0.3 \\
\hline $\begin{array}{l}\text { Guide thimble } \\
(\sim \text { SS-321) }\end{array}$ & $\geq 207$ & $\geq 517$ & 200 & 0.3 \\
\hline $\begin{array}{l}\text { Fuel rod } \\
\text { (Zircaloy-4) }\end{array}$ & $\geq 240$ & $\geq 415$ & 200 & 0.42 \\
\hline
\end{tabular}

of the fuel assembly has been fixed, i.e. nodes along Y-axis are fixed in X-direction;

- the applied axial tensile load of $9800 \mathrm{~N}$ has been divided onto 20 guide thimbles and the load of each guide thimble is distributed on the nodes associated with the upper end of the guide thimble in Z-direction;

- all nodes associated with the upper end of the guide thimbles have been coupled in load direction, i.e. Zdirection, other degrees of freedom are set to be zero;

- the weight of fuel rod, $2.114 \mathrm{~kg}$ or $21 \mathrm{~N}$, is applied on each fuel rod which is further distributed on the nodes associated with the bottom end of the fuel rod in Z-direction.

FE model, including all above-mentioned boundary conditions, is presented in Figure 4.

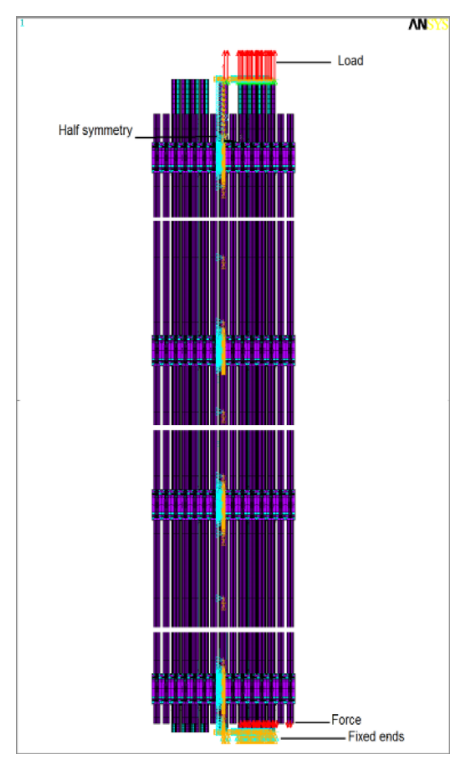

Fig. 4. Applied boundary conditions (element plot 3D).

\section{Experimental model}

The fuel assembly bears a variety of loads as discussed earlier. Therefore, fuel assembly should have adequate stiffness, strength and dimensional stability to reduce the damage and large elongation failure due to the fuel assembly handling or lifting. This test will provide the basis for the design of fuel assembly, manipulator crane and container and tools which are used in the fuel handling process. In the present study, we have considered the axial tensile test of fuel assembly which has been performed on the prototype full-scale test specimen of fuel assembly at room temperature as shown in Figure 1 except that the pellets of fuel rods are dummy but they are similar in the geometry and weight.

The test facility contains a frame structure of high stiffness and strength. The frame structure is made through welding of the channels beams and steel plates. A convenient load applying system is also developed in order to measure the signals under loading conditions during the test. The force transducer of BLR-1 type is used for the tensile load to measure the force. Foil-type strain gauges of $2 \times 3 \mathrm{~mm}$ are used for the strain measurement. The resistance of strain gauges is $120 \pm 0.2 \Omega$, and its sensitivity coefficient is $2.17 \pm 1 \%$. The material, silicone type, which solidifies at room temperature, is used for moisture proof seal [6].

First of all, the test specimen is placed within the calibrated leveled support plates of load applying system and the parallelism of the support plates is adjusted within the specified tolerances of the fuel assembly. Then maximum tensile load of $9800 \mathrm{~N}$, with load increment of $1960 \mathrm{~N}$, is applied on the loading plate, which is divided onto 20 guide thimbles in axial direction.

All guide thimbles are similar in material, geometry and loading conditions, therefore, the strain gauges are mainly pasted on five levels of the guide thimbles. These levels are located on the two corners of one side/face of the fuel 


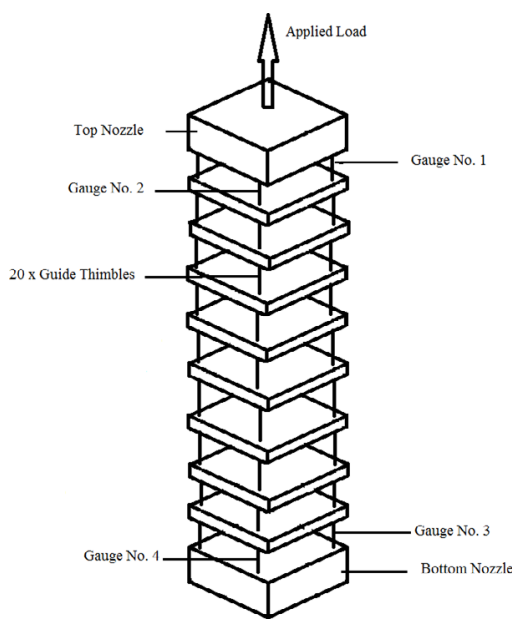

Fig. 5. Strain gauge locations.

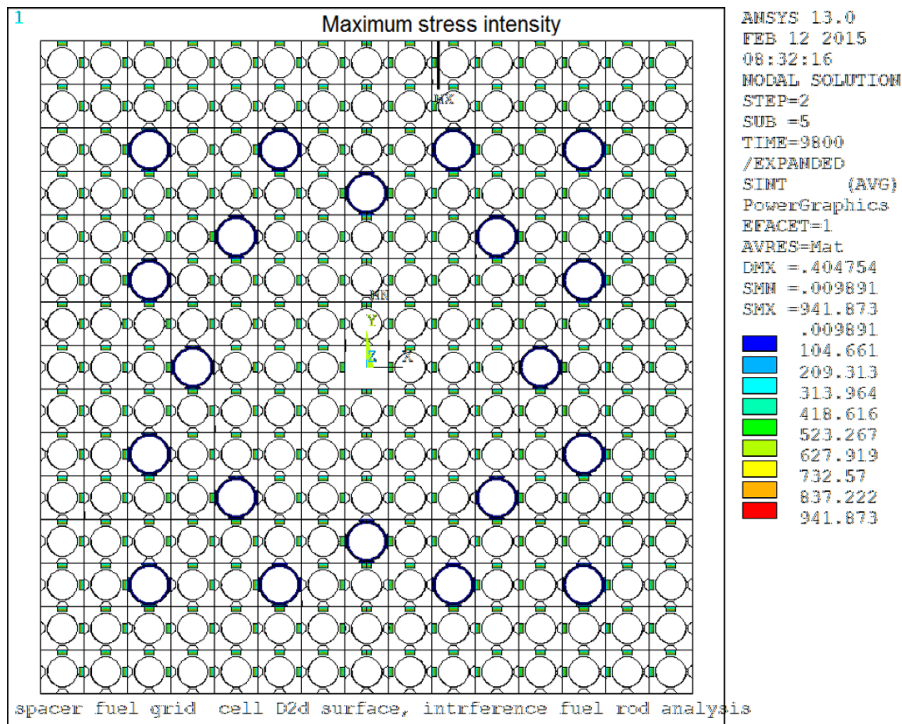

Fig. 6. Plot of nodal stress intensity of fuel assembly.

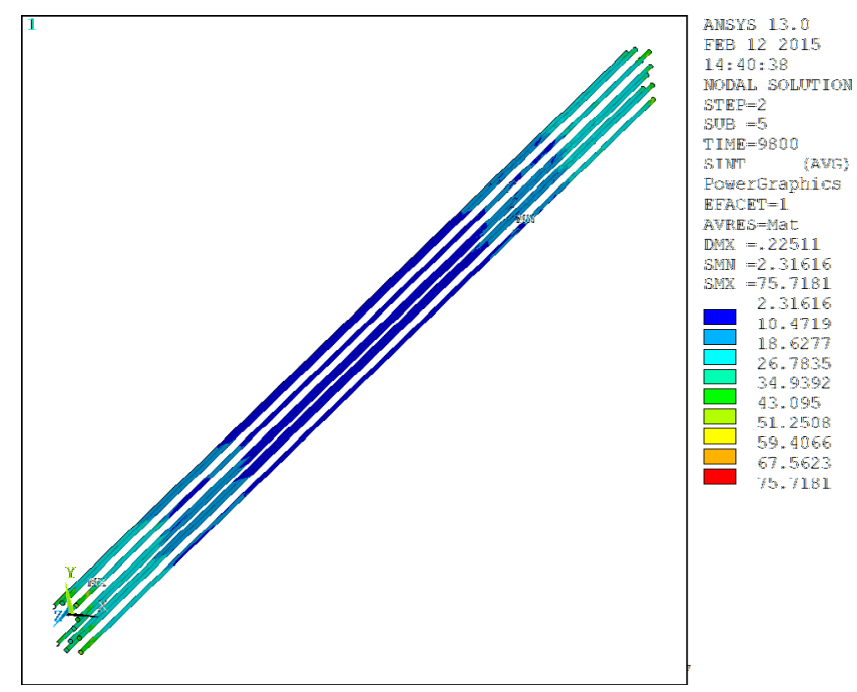

Fig. 7. Plot of nodal stress intensity of guide thimbles.

assembly skeleton (i.e., before insertion of fuel rods in the test specimen) and after pasting all gauges fuel rods are inserted in the prototype fuel assembly test specimen. Mainly, two critical measuring points or levels on the test specimen, determined through FE analysis, have been considered in the present study. The strain gauges, pasted on the upper and lower end positions of the guide thimbles, i.e. near to top and bottom nozzles of the fuel assembly, have been used to measure the local stress concentration at the root of the guide thimbles. The detailed methodology and arrangement of the strain gauges is illustrated in Figure 5 .

\section{Discussion of FE and test results}

- Mesh density is the most important parameter affecting both accuracy and convergence behavior. Therefore, a sensitivity analysis has been performed to set a mesh refinement level at which converged and more accurate results are obtained.

- Stress intensity is the difference between the algebraically largest and smallest principal stresses at a given point [7]. It is a representative of both stresses primary membrane $(\mathrm{Pm})$ and bending $(\mathrm{Pb})$ [8]. The max. nodal stress intensity at the fuel assembly, 941.9 MPa, under applied load of $9800 \mathrm{~N}$ or $2 \mathrm{~g}$, is located at the middle of top surface of the lower arc of spring, as shown in Figure 6 .

The value of stress intensity is less than the design stress limit, which is equal to the yield strength [7] of the grid material, $1034 \mathrm{MPa}$ [9].

- The max. nodal stress intensity at the guide thimbles, 75.7 MPa, under applied max. load of $2 \mathrm{~g}$, is located at the outer surface of guide thimble near the top nozzle, as shown in Figure 7.

The value of stress intensity is also less than the design stress limit of the guide thimble material, $207 \mathrm{MPa}$ [10]. 


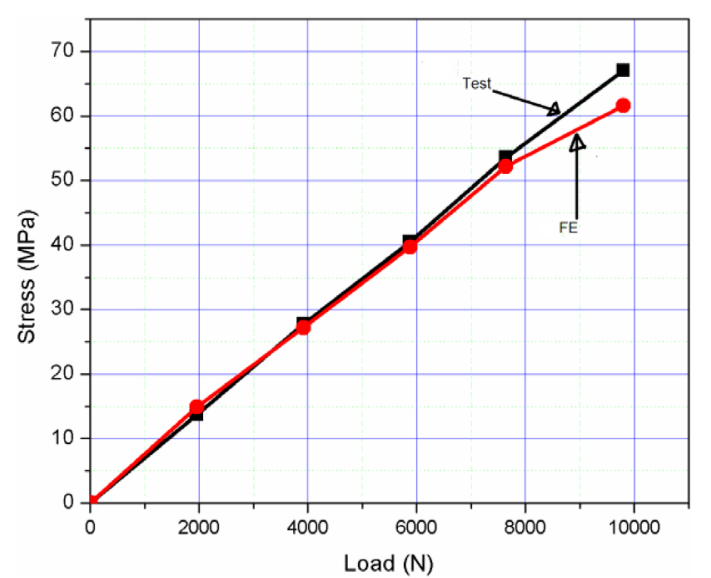

Fig. 8. Test \& FE analysis results at gauge-1 location.

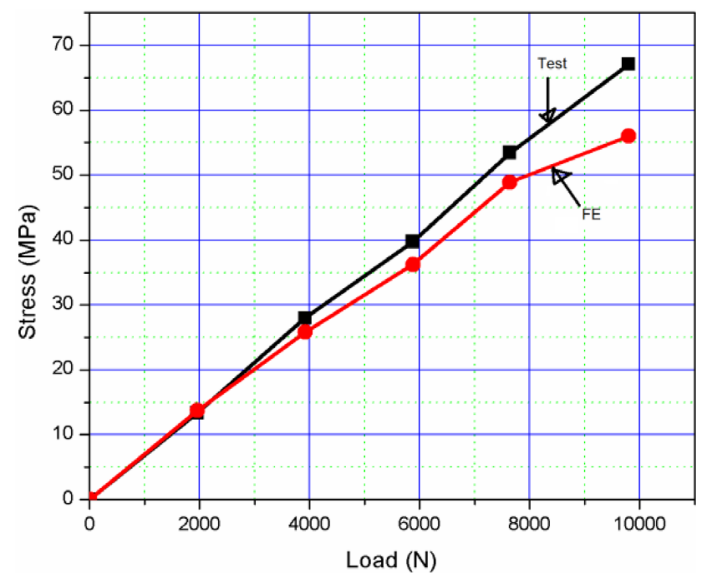

Fig. 9. Test \& FE analysis results at gauge-2 location.

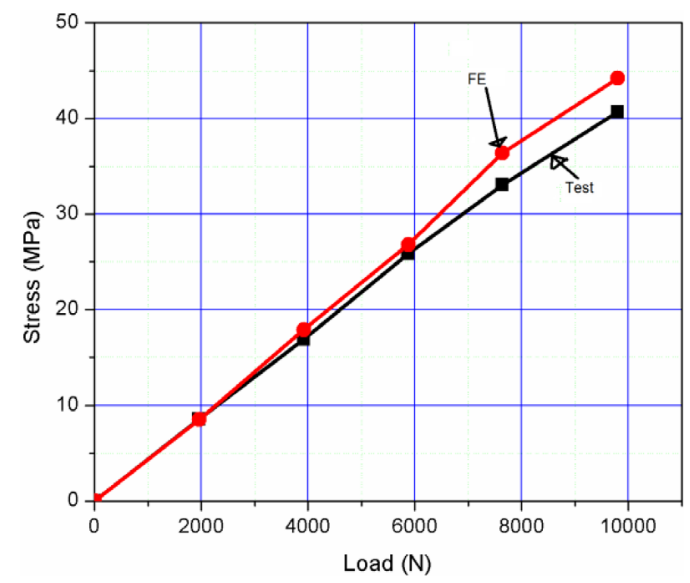

Fig. 10. Test \& FE analysis results at gauge-3 location.

- The axial tensile stresses obtained through strain gauges (Nos. 1-4), under tensile load of $9800 \mathrm{~N}$ or $2 \mathrm{~g}$ (fuel assembly handling load), applied with a load step of $1960 \mathrm{~N}$, are compared with the FE results at the same loads and locations, as illustrated in Figures 8-11.

As seen from Figures 8-11, it can be observed that the stress in fuel assembly in axial direction, obtained from both studies, increases approximately linear with the

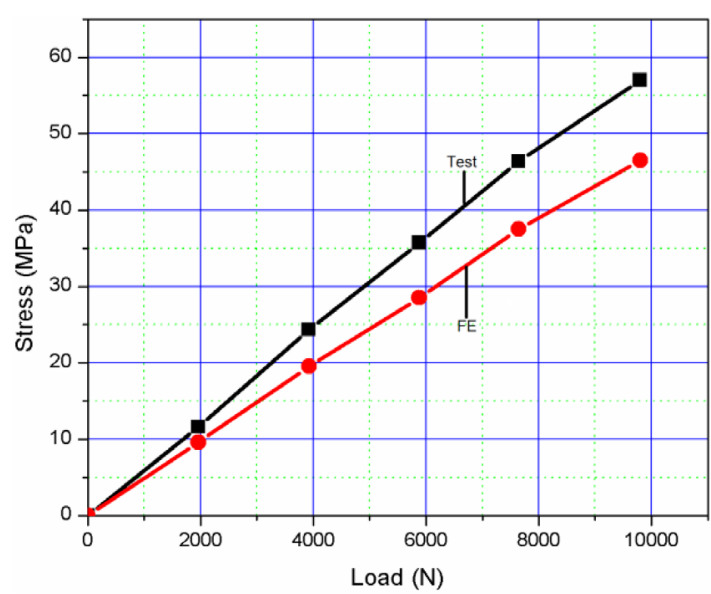

Fig. 11. Test \& FE analysis results at gauge-4 location.

Table 3. Comparison of FE analysis and test results at a load of $9800 \mathrm{~N}(2 \mathrm{~g})$.

\begin{tabular}{|c|c|c|c|}
\hline \multirow[t]{2}{*}{ Gauge No. } & \multicolumn{2}{|c|}{ Stress $(\mathrm{MPa})$} & \multirow{2}{*}{$\begin{array}{l}\text { \% Error } \\
\text { (Test \& FE analysis) }\end{array}$} \\
\hline & FE analysis & Test & \\
\hline 1 & 61.6 & 67.1 & 8 \\
\hline 2 & 56 & 67.1 & 17 \\
\hline 3 & 44.2 & 40.7 & -9 \\
\hline 4 & 46.5 & 57.0 & 18 \\
\hline
\end{tabular}

$\%$ Error: [(experimental $-\mathrm{FE}$ analysis $) /$ experimental $] \times 100$.

increase in load as well as the results of the both studies (FE and test) are also comparable.

- The percentage errors between the analytical and test results are calculated at max. applied tensile load of $9800 \mathrm{~N}$ or $2 \mathrm{~g}$, as shown in Table 3.

From Table 3, the calculated error between the FE analysis and Test results on gauge Nos. 1 and 3 lies within the error band of $\pm 9 \%$ and that on gauge Nos. 2 and 4 lies within the error band of $\pm 18 \%$. The percentage of error may be minimized by increasing the mesh density at the cost of computational time.

- The max. elongation of fuel assembly obtained from both studies, FE and test under applied max. axial tensile load $(9800 \mathrm{~N})$ are $0.38 \mathrm{~mm}$ and $0.36 \mathrm{~mm}$, respectively. The calculated error between the FE analysis and test results of fuel assembly elongation at max. tensile load lies within the error band of $\pm 5 \%$. The elongation behaviours, obtained from both studies, are plotted in Figure 12.

- From Figure 12 it can be seen that the elongation in fuel assembly in axial direction, obtained from both studies, increases approximately linearly with the increase in load. which means that fuel assembly may not permanently elongate till application of the max. load of $9800 \mathrm{~N}$.

- Therefore, the stresses (on the majority of gauges) and deformation obtained through test are comparable with the FE results which validate the FE methodology. 


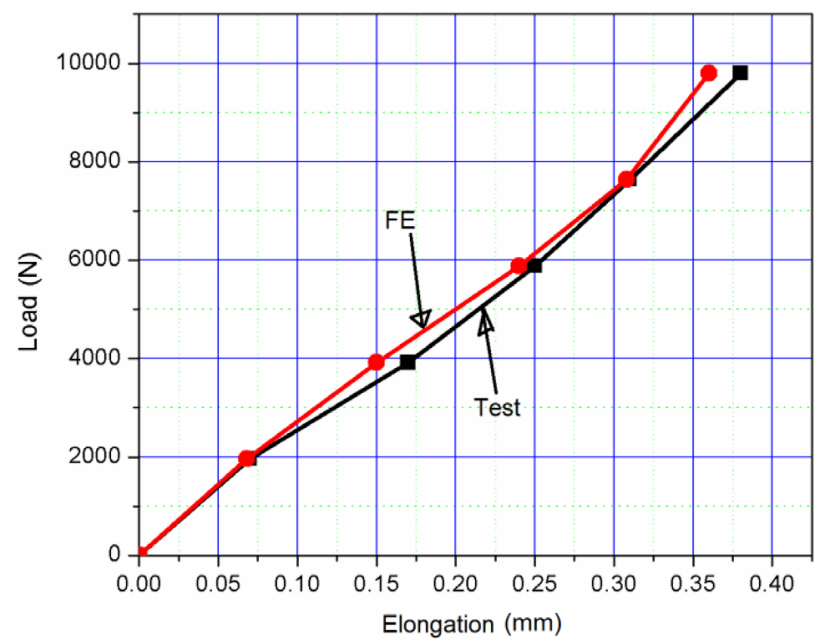

Fig. 12. Elongation behavior of FE analysis and test results.

\section{Conclusions}

The values of maximum stresses at the fuel assembly and guide thimbles, obtained from the Test and FE analysis, are less than the design stress limit of the grid and guide thimble materials. Therefore, fuel assembly is satisfying the structural integrity criterion at a load of $9800 \mathrm{~N}(2 \mathrm{~g})$.

This study has provided a good confidence level for verification of CHASNUPP-1 fuel assembly design at room temperature, which can be useful for any change required in the modified fuel assembly design, such as different material, number of grids/span, before conducting the confirmatory tests, and may be very helpful for improving the safety and reliability of fuel assembly design.

\section{References}

1. W.N. Elahi, A.A. Siddiqui, G. Murtaza, Fuel rod-to-support contact pressure and stress measurement for CHASNUPP-1 (PWR) fuel, Int. J. Nucl. Eng. Des. 241, 32 (2011)

2. W.N. Elahi, A.A. Siddiqui, G. Murtaza, Structural integrity assessment of spot weld joints between spacer grid and guide thimble of PWR fuel assembly, Tech. Report DGNPF-TR/ 012,2010

3. W.N. Elahi, G. Murtaza, A.A. Siddiqui, Structural integrity assessment and stress measurement of CHASNUPP-1 Fuel assembly skeleton, Int. J. Nucl. Eng. Des. 266, 55 (2014)

4. W.N. Elahi, G. Murtaza, Structural integrity assessment and stress measurement of CHASNUPP-1 Fuel assembly, Int. J. Nucl. Eng. Des. 280, 130 (2014)

5. Y. Zhang et al., Fuel assembly design report, SNERDI, China, 1994

6. SNERDI Tech. Doc., Mechanical strength and calculation for fuel assembly, Technical Report F3.2.1, China, 1994

7. ASME, Boiler and pressure vessel code, Section III, Division 1, Subsection NB, Article NB-3000, 2001

8. Help manual of the ANSYS version13.0, 2012

9. ASTM, Standard specification for precipitation hardening nickel alloy (UNSN07718) plate, sheet, and strip for high temperature service, B 670-80, USA, 2013

10. ASTM, Standard specification for seamless stainless steel mechanical tubing, A 511-04, USA, 2004

Cite this article as: Waseem, Ghulam Murtaza, Ashfaq Ahmad Siddiqui, Syed Waseem Akhtar, Structural integrity assessment and stress measurement of CHASNUPP-1 fuel assembly. Part A: under tensile loading condition, EPJ Nuclear Sci. Technol. 2, 18. $(2016)$ 